\title{
Research on Influencing Factors of Foreign Assets Common Benefit Mechanism of Tobacco Farmer Cooperatives Based on Interpretive Structural Model
}

\author{
Jun Liu ${ }^{1, a^{*}}$, Feng Wang ${ }^{2, b}$, Bing Zhou ${ }^{2, c}$ \\ ${ }^{1}$ Guizhou University of Finance and Economics, Guiyang 550025 \\ ${ }^{2}$ Branch of Tobacco Company in Southwest Guizhou Province, Xingyi 562400 \\ aemail: liujunsucceed@163.com, bemail: 479095320@qq.com, email: 5267865@qq.com
}

\begin{abstract}
Keywords: Farmers Cooperatives; Foreign Assets; Interpretative Structural Model; Influence Factors
\end{abstract}

Abstract: This paper uses literature metrology method to statistical analyze related literatures. 14 influencing factors of foreign assets common benefit mechanism of tobacco farmer cooperatives are determined and selected from predecessors' research achievements. Relational structure of 14 influencing factors are analyzed by ISM model. Results show that collective asset security, operational efficiency of foreign assets, flexibility of collective assets application, foreign assets allocation and foreign assets preservation are fundamental factors. The study has important significance for grasping the formation, development and evolution mechanism of foreign assets common benefit mechanism of tobacco farmer cooperatives.

\section{Introduction}

As main body of market, vitality and competitiveness of farmer cooperatives depends largely on the amount of assets owned or controlled. Cooperative itself is unable to form substantial assets. To help cooperatives breakthrough asset plight, many order companies give financial support, require cooperatives to quantify the subsidy to each member, realize preferences and wide benefit of all members. Tobacco industry is a typical order agriculture. Tobacco companies implement orders planting and subsidy system to realize GSP and fairness of subsidy input. Tobacco companies guide all farmers set up farmers cooperatives, subsidies farm machinery, greenhouse, vehicles and other assets to cooperatives. Cooperatives reuse these assets provide low-cost services to farmers member.

In reality, some farmers cooperatives did not implement quantitative distribution of external subsidy assets. Its beneficiaries are often just a handful of core members. The amount of money in member account column "quantify share of external subsidy funds"" quantify share of donated property" is casual, so cooperative cohesion decline. Therefore, research on influencing factors of foreign assets common benefit mechanism of tobacco farmer cooperatives is especially important.

At home and abroad, there are few studies on foreign assets common benefit mechanism of tobacco farmer cooperatives. Wang Li (2014) pointed out that the development form of collective economy was rural community stock cooperative. Its essence was to quantify collective assets to each rural community members who accord with certain conditions. So influencing factors of foreign assets common benefit mechanism of tobacco farmer cooperatives mainly have flexibility of collective assets application, collective asset income rights, collective asset compensation rights, collective asset mortgage, collective asset security right ${ }^{[1]}$.

Kong Youli (2014), in the analysis of property rights of rural community share economic cooperatives, pointed out that, in most developed rural areas, there are not directly link between collective assets and farmers interests, assets operation was bad, collective assets massively lost. Therefore, influencing factors of foreign assets common benefit mechanism of tobacco farmer cooperatives mainly have management efficiency of foreign assets, foreign assets protection, foreign assets appreciation, foreign assets allocation, foreign assets share ${ }^{[2]}$. Shandong province, through collective property rights reform, quantifies collective asset shares to organization members of village economic. The shares held by collective economic organization members form 
community economic professional cooperatives. Community economic cooperatives as an independent legal person and market players, bear collective asset management, operation and investment functions, establish collective property right system with clear subject and ownership, clear responsibility and authority, strict protection ${ }^{[3]}$. Chinese Rural Cooperative Economic Management Institute, Zhang Xiaoshan (2015) proposed collective assets cure equity, land rights and real right by right confirmation, registration and certification work, clear property rights. Its essence is to determine the shares of collective economic organization members to collective assets or resources at a certain point, determine the fairness of starting point. In the future, collective economy development direction will be from closed to open, from curing to flow, curing is to get a better flow, on the basis of clear property rights, the joint-stock form of cooperation is conducive to promoting the flow of equity, land rights and real right, increases funding, expands stocks ${ }^{[4]}$. We pay relatively little attention on orders enterprises investment subsidies or donations, attention to property particularity of cooperatives foreign assets is also not enough.

\section{Influencing Factors Determination of Foreign Assets Common Benefit Mechanism of Tobacco Farmer Cooperatives}

Literature metrology studies quantity, quality and application of essence and structure about various types of documents using theory and method of mathematics, statistics and logic ${ }^{[5]}$. In this paper, this method is used to determine and select influencing factors of foreign assets common benefit mechanism. Chinese journal full-text database did not have papers about influencing factors of foreign assets common benefit mechanism of tobacco farmer cooperatives before 2000. There are 34 papers of which title contain "influence factors of foreign assets common benefit mechanism of tobacco farmer cooperatives" in Chinese journal full-text database from January 2000 to July 2015. With literature metrology method, we analyzed influencing factors that were studied or mentioned in various literatures, and got 14 important factors, including flexibility of collective assets application, collective asset income rights, collective asset compensation rights, collective asset mortgage, collective asset security right, management efficiency of foreign assets, foreign assets protection, foreign assets appreciation, foreign assets allocation, foreign assets share, clear property rights, equity curing, land rights curing and real right curing.

\section{Relationship Structure Analysis of Influencing Factors}

\subsection{Determination of Relationship Between Various Factors}

In order to analyze the impact of these factors, we establish a interpretation structure model ${ }^{[6]}$. First, combined with previous research results, we clarify logical relationship between various factors, as shown in figure 1. The "A" represents the row factors have a direct impact on the column factors. The "V" represents the column factors have a direct impact on the row factors. "X" represents the row factors and the column factors have a direct impact on each other. "O" represents the row factors and the column factors do not have a direct impact on each other.

\begin{tabular}{|c|c|c|c|c|c|c|c|c|c|c|c|c|c|c|c|}
\hline$S_{1}$ & $S_{2}$ & $S_{3}$ & $S_{4}$ & $S_{5}$ & $S_{6}$ & $S_{7}$ & $S_{8}$ & $S_{9}$ & $S_{10}$ & $S_{11}$ & $S_{12}$ & $S_{13}$ & $S_{14}$ & $S_{15}$ & \\
\hline & $A$ & $O$ & $O$ & $O$ & $O$ & $X$ & $O$ & $O$ & $O$ & $O$ & $O$ & $O$ & $O$ & $A$ & $S_{1}$ \\
\hline & & $O$ & $O$ & $V$ & $O$ & $V$ & $V$ & $V$ & $O$ & $O$ & $O$ & $O$ & $O$ & $A$ & $S_{2}$ \\
\hline & & & $O$ & $A$ & $O$ & $X$ & $O$ & $O$ & $A$ & $O$ & $O$ & $A$ & $O$ & $A$ & $S_{3}$ \\
\hline & & & & $O$ & $O$ & $O$ & $O$ & $O$ & $O$ & $O$ & $O$ & $O$ & $O$ & $A$ & $S_{4}$ \\
\hline & & & & & $O$ & $O$ & $O$ & $V$ & $O$ & $O$ & $O$ & $O$ & $O$ & $A$ & $S_{5}$ \\
\hline & & & & & & $O$ & $O$ & $A$ & $A$ & $O$ & $O$ & $O$ & $O$ & $A$ & $S_{6}$ \\
\hline & & & & & & & $A$ & $O$ & $O$ & $A$ & $A$ & $O$ & $O$ & $A$ & $S_{7}$ \\
\hline & & & & & & & & $V$ & $O$ & $O$ & $O$ & $O$ & $O$ & $A$ & $S_{8}$ \\
\hline & & & & & & & & & $A$ & $O$ & $O$ & $O$ & $O$ & $A$ & $S_{9}$ \\
\hline & & & & & & & & & & $O$ & $A$ & $A$ & $O$ & $A$ & $S_{10}$ \\
\hline & & & & & & & & & & & $A$ & $V$ & $O$ & $A$ & $S_{11}$ \\
\hline & & & & & & & & & & & & $A$ & $O$ & $A$ & $S_{12}$ \\
\hline & & & & & & & & & & & & & $O$ & $A$ & $S_{13}$ \\
\hline & & & & & & & & & & & & & & $A$ & $S_{14}$ \\
\hline
\end{tabular}

Fig. 1 Logical Relationship Between Various Factors 
According to Figure 1, we can get correlation matrix $\mathrm{R}$ which is 15 order square matrix. Elements of $\mathrm{R}$ are defined as

$$
\begin{aligned}
r_{i j} & =\left\{\begin{array}{llllllllllllll}
1, & S_{i} \text { directly impact } S_{j} \\
0, & \text { Sim directly impact } S_{j}, \quad(i, j=1,2, \cdots, 15), \text { then, }
\end{array}\right. \\
R & =\left[\begin{array}{lllllllllllllllllllllllll}
0 & 1 & 0 & 0 & 0 & 0 & 1 & 0 & 0 & 0 & 0 & 0 & 0 & 0 & 1 \\
0 & 0 & 0 & 0 & 0 & 0 & 0 & 0 & 0 & 0 & 0 & 0 & 0 & 0 & 1 \\
0 & 0 & 0 & 0 & 1 & 0 & 1 & 0 & 0 & 1 & 0 & 0 & 1 & 0 & 1 \\
0 & 0 & 0 & 0 & 0 & 0 & 0 & 0 & 0 & 0 & 0 & 0 & 0 & 0 & 1 \\
0 & 1 & 0 & 0 & 0 & 0 & 0 & 0 & 0 & 0 & 0 & 0 & 0 & 0 & 1 \\
0 & 0 & 0 & 0 & 0 & 0 & 0 & 0 & 1 & 1 & 0 & 0 & 0 & 0 & 1 \\
1 & 1 & 1 & 0 & 0 & 0 & 0 & 1 & 0 & 0 & 1 & 1 & 0 & 0 & 1 \\
0 & 1 & 0 & 0 & 0 & 0 & 0 & 0 & 0 & 0 & 0 & 0 & 0 & 0 & 1 \\
0 & 1 & 0 & 0 & 1 & 0 & 0 & 1 & 0 & 1 & 0 & 0 & 0 & 0 & 1 \\
0 & 0 & 0 & 0 & 0 & 0 & 0 & 0 & 0 & 0 & 0 & 1 & 1 & 0 & 1 \\
0 & 0 & 0 & 0 & 0 & 0 & 0 & 0 & 0 & 0 & 0 & 1 & 0 & 0 & 1 \\
0 & 0 & 0 & 0 & 0 & 0 & 0 & 0 & 0 & 0 & 0 & 0 & 1 & 0 & 1 \\
0 & 0 & 0 & 0 & 0 & 0 & 0 & 0 & 0 & 0 & 1 & 0 & 0 & 0 & 1 \\
0 & 0 & 0 & 0 & 0 & 0 & 0 & 0 & 0 & 0 & 0 & 0 & 0 & 0 & 1 \\
0 & 0 & 0 & 0 & 0 & 0 & 0 & 0 & 0 & 0 & 0 & 0 & 0 & 0 & 0
\end{array}\right]
\end{aligned}
$$

\subsection{Relationship Between Different Levels of Various Factors}

The data of $R\left(S_{i}\right)$ and $A\left(S_{i}\right)$ are shown in table 1.

Table 1 The First Level of Reachable Collection and Antecedent Collection of Influencing Factors

\begin{tabular}{llll}
\hline$S_{i}$ & $R\left(S_{i}\right)$ & $A\left(S_{i}\right)$ & $R\left(S_{i}\right) \cap A\left(S_{i}\right)$ \\
\hline 1 & $1,2,3,5,7,8,10,11,12,13$, & $1,3,7$ & $1,3,7$ \\
2 & 2,15 & $1,2,3,5,6,7,8,9$ & 2 \\
3 & $1,2,3,5,7,8,10,11,12,13$, & $1,3,7$ & $1,3,7$ \\
4 & 4,15 & 4 & 4 \\
5 & $2,5,15$ & $1,3,5,6,7,9$ & 5 \\
6 & $2,5,6,8,9,10,11,12,13,15$ & 6 & 6 \\
7 & $1,2,3,5,7,8,10,11,12,13$, & $1,3,7$ & $1,3,7$ \\
8 & $2,8,15$ & $1,3,6,7,8,9$ & 8 \\
9 & $2,5,8,9,10,11,12,13,15$ & 6,9 & 9 \\
10 & $10,11,12,13,15$ & $1,3,6,7,9,10$ & 10 \\
11 & $11,12,13,15$ & $1,3,6,7,9,10,11,12,13$ & $11,12,13$ \\
12 & $11,12,13,15$ & $1,3,6,7,9,10,11,12,13$ & $11,12,13$ \\
13 & $11,12,13,15$ & $1,3,6,7,9,10,11,12,13$ & $11,12,13$ \\
14 & 14,15 & 14 & 14 \\
15 & $\underline{15}$ & $1,2,3,4,5,6,7,8,9,10,11,12,13,14$, & $\underline{15}$ \\
\hline
\end{tabular}


(1)The first node of influencing factors can be obtained from data in table 1: $L_{1}=\{15\}$.

(2) Delete line 15 and column 15 of reachable matrix, get the second node: $L_{2}=\{2,4,11,12,13,14\}$.

According to above analysis, we establish interpretive structural model of influencing factors of foreign assets common benefit mechanism of tobacco farmer cooperatives, as shown in figure 2 .

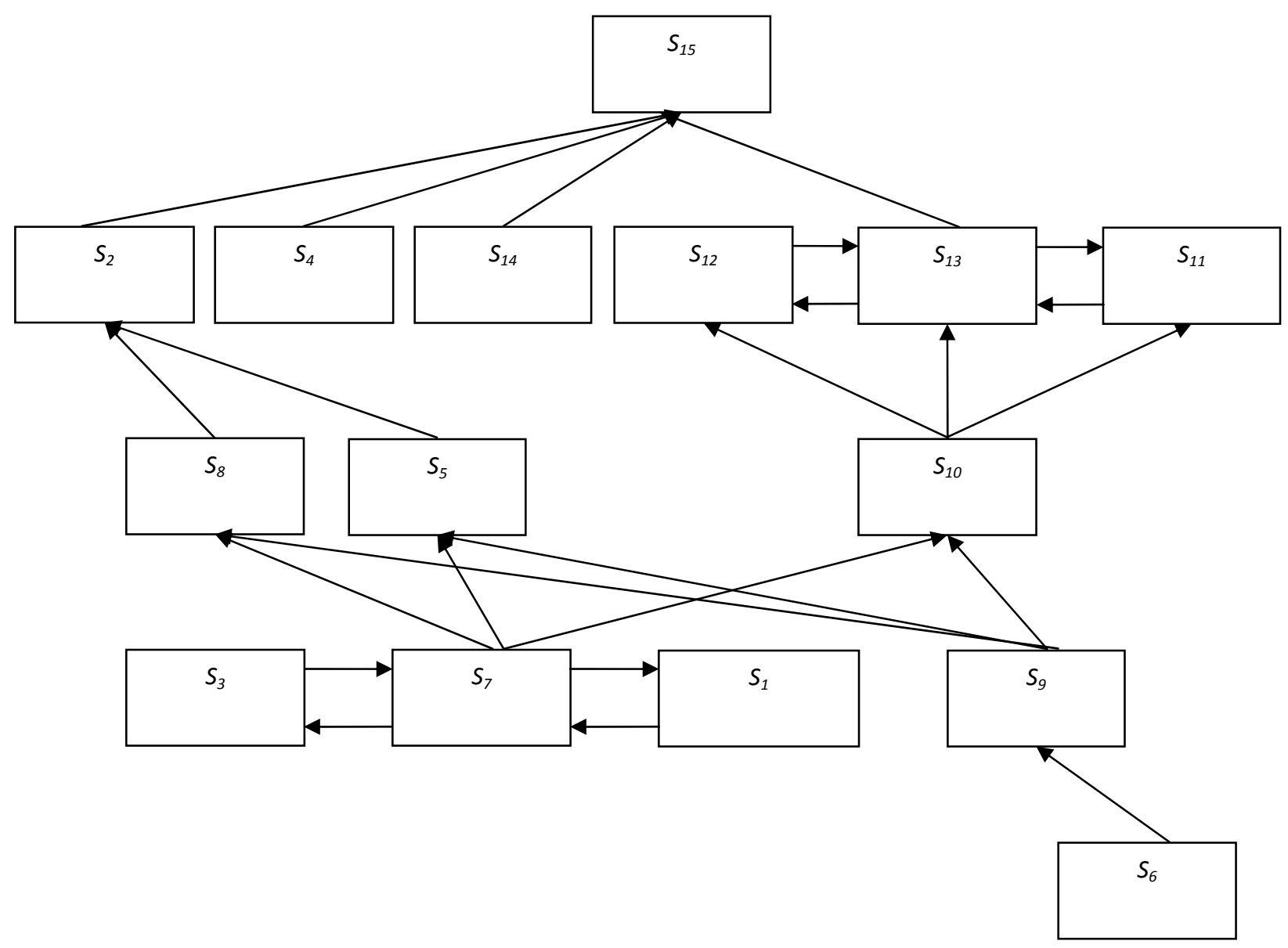

Fig. 2 Interpretive Structural Model

\section{Conclusion}

As shown in figure 2, foreign assets common benefit mechanism of tobacco farmer cooperatives is a hierarchical structure with 5 levels. The first level is foreign assets common benefit mechanism of tobacco farmer cooperatives $\left(S_{15}\right)$.The second level includes output value per collective asset income rights $\left(S_{2}\right)$, collective asset mortgage $\left(S_{4}\right)$, real right curing $\left(S_{14}\right)$, equity curing $\left(S_{12}\right)$, land rights curing $\left(\mathrm{S}_{13}\right)$, clear property rights $\left(S_{11}\right)$. The third level includes appreciation of foreign assets $\left(S_{8}\right)$, collective asset compensation rights $\left(S_{5}\right)$, foreign assets share $\left(S_{10}\right)$. The fourth level includes collective asset security right $\left(S_{3}\right)$, management efficiency of foreign assets $\left(S_{7}\right)$, flexibility of collective assets application $\left(S_{1}\right)$, foreign assets allocation $\left(S_{9}\right)$. The fourth level includes foreign assets protection $\left(S_{6}\right)$.

Research on the relationship structure between influencing factors, we can find out surface direct influencing factors, middle and indirect influencing factors, fundamental influencing factors. Collective asset security right, management efficiency of foreign assets, flexibility of collective assets application, foreign assets allocation and foreign assets protection are fundamental influencing factors, which produce deep and fundamental impact on the formation, development 
and evolution of foreign assets common benefit mechanism of tobacco farmer cooperatives. Distinguishing function levels and their relationship of each influencing factor has an important significance for grasping the formation, development and evolution mechanism of foreign assets common benefit mechanism of tobacco farmer cooperatives.

\section{Acknowledgements}

Research on evaluation of tobacco farmers classification and differential management in southwestern Guizhou (2011-15); Study on the mechanism of foreign assets of tobacco farmers cooperatives inclusive (2015-9); Guizhou Province Science and Technology Fund project ( Qiankehe J [2015] No. 2028); Science and technology project of China National Tobacco Corp Guizhou Branch (201224); National social science fund project (14CJL032)

\section{References}

[1] Wang Li. New opportunities for the development of farmer cooperatives [N]. Chinese agricultural mechanization Herald,2014-12-09.

[2] Kong YouLi, Liu Huazhou. Research on property rights of shares economic cooperatives in rural communities -- a case study shares Cooperative of Village Collective Economic Organizations in Jiangsu province [J]. Chinese Agricultural Science Bulletin,2014,23:420-426.

[3] Lin Jianhua, Zhao Hongbo. New development of farmer cooperatives in Shandong Province[J]. Chinese farmer cooperatives,2014,02:19-21.

[4] Zhang Xiaoshan. Some thoughts on promoting the healthy development of farmer cooperatives in China [J].Chinese farmer cooperatives,2015,04:44-46.

[5] He Guangguo.The Introduction of Bibliometrics[M].Taibei: San Min Book Co.,Ltd, 1994. $8-9$.

[6] Wang Yingluo. Systems Engineering Theory, Methods and Applying[M].Beijing: China Higher Education Press, 1998. 35-57. 